\title{
ODORSENSE: MEASURING, ASSESSMENT AND ALERTING THE HEALTH EFFECTS OF ODOR POLLUTION
}

Santhosh B. Panjagal

Research Scholar, VTU Belagavi. Associate Processor, KEC-Kuppam, (India).

E-mail: santupanjagal@gmail.com

ORCID: https://orcid.org/0000-0002-6263-1727

G. N. Kodanda Ramaiah

Professor \& Dean, KEC-Kuppam, (India).

E-mail: gnk.ramaiah@gmail.com

ORCID: https://orcid.org/0000-0002-1692-9629

Recepción: 09/12/2020 Aceptación: 02/03/2021 Publicación: 07/05/2021

\section{Citación sugerida:}

Panjagal, S. B., y Ramaiah, G. N. K. (2021). OdorSense: Measuring, Assessment and Alerting the Health Effects of Odor Pollution. 3C Tecnología. Glosas de innovación aplicadas a la pyme, Edición Especial, (mayo 2021), 97-113. https://doi.org/10.17993/3ctecno.2021.specialissue7.97-113 


\section{ABSTRACT}

Nowadays there is an increased conflict between residents and government bodies /or industries due to unpleasant or offensive Odor smells emanating from different sources, interfacing with person's enjoyment of life as they are frequent and persistent. The main concern among all the residents is the health effects of toxic Odor gases (like, ammonia, Sulphur dioxide, nitrogen, hydrogen sulphide) released from the waste dumping sites, drainages, food \& meat processing industries, etc., causing dreadful diseases to the living beings. There is urgent need of an intelligent mechanism, which allows every common people access the Odor pollution information through user friendly applications. Hence the main objective of the proposed research work was to develop an intelligent mechanism for detecting, measuring and alerting the health effects of Odor pollution. The research work follows design o an artificial olfaction system based electronic nose using low cost, low power and improved accuracy sensors for detection and real-time measurement of Odor concentrations at various sources of Odor emissions, uploading the Odor concentrations to Io $\mathrm{T}$ cloud for remote monitoring and alerting. User friendly interface application developed for providing real time information about the Odor levels at the desired source and alerting the health effects if the Odor concentration levels increases above the threshold levels.

\section{KEYWORDS}

Odor pollution, Odor Measurement, Odor concentration, Artificial olfaction system (E-Nose), User Interface (Mobile Application), Health survey, IoT Cloud, Risk Assessment. 


\section{INTRODUCTION}

Odor pollution is most complex problem due to its distinctly different characteristics, as they possess different physical and chemical properties, and they are present at a concentration ranges from high parts per million (ppm) to low parts per billion (ppb) (Shinde et al., 2017). Till date very little attention has been paid towards Odor pollution issues in India, therefore Odor pollution and its problems has become objectionable proportion with the growing population, industrialization, and urbanization. The main cause of Odor pollution and its problems is due to urbanization with improper sanitation facilities (Nicolas et al., 2006).

At the same time there are many sources which contributes to Odor pollution, they are classified as 1. Point sources (vents, stacks, and exhausts), 2. Area sources (Sewage treatment plants, wastewater treatment plants, solid waste landfill, composting, household manure settling lagoons, etc.) (Elwell, 2001; Nicolas, 2006; Pagans, 2006), 3. Building sources (Pig sheds, hog confinement chickens) (Misselbrook et al., 1993) 4. Fugitive sources (soil bed or bio-filter surfaces). Hence, Odor can arise from many sources, most are manmade garbage or unscientific dumping on vacant lands (Di et al., 2013; CPCB, 2007).

The Major Odor pollution are Industries Pulp \& Paper, Fertilizer, Pesticides, Tanneries, Sugar \& Distillery, Chemical, Dye \& Dye Intermediates, Bulk Drugs \& Pharmaceuticals etc., Large Livestock operations, Poultry/chicken Farms (Hayes et al., 2006), Slaughterhouses, Food processing industries, Agricultural activities like decaying of vegetation, production and application of compost etc. (Yan-li Zhu, 2016; CPCB, 2007), In urban and metropolitan areas, improper maintenance of public amenities like toilets, bus/railway stations, hospitals, shopping complex etc. generate pungent Odor, which affects the peoples as well as neighborhood residents. Important issue is Odor cannot escape from Congested markets, thus causing problems to shop-keepers as well as to customers (CPCB, 2007).

Generally, the most common Odors released from various sources are putrid, pungent, or musky etc., from these Odors some toxic gases are also released like ammonia, Sulphur dioxide, hydrogen sulfide (Sarkar et al., 2002) which can cause dreadful diseases to living beings, hence strong Odors released from different sources, causes irritation to eyes, nose, throat or lungs, nausea, loss of memory \& sleep, coughing due burning sensation, headache, 
dizziness, wheezing or other breathing/respiratory problems (NIOSH, 2007, OSHA, 2011, ACGIH, 2021).

Now the Odor pollution nuisance has become most important environmental issue among all pollution problems, leading to more number complaints and conflicts between residents, industries and government (Nicolas et al., 2006; Takano, 2014). Therefore, demanding more stringent policies to regulate Odor annoyance and need for continuous efforts to manage and limit the Odor exposure in the neighborhood to identifying, quantifying and monitoring the Odor emission (Wenjing et al., 2015).

Generally, there are various measurement techniques to quantify the Odor concentrations, among them some techniques (human olfaction and conventional analytical) provide only perception real Odor and mixture composition, but not applicable for continuous real-time measurement in the field and also don not provide global information relating to Odor perception (Nicolas et al., 2006). There is a need to develop an appropriate new system to measure and monitor Odor concentration based on devices rather than depending on biological human olfaction involving trained human panelists (Deshmukh et al., 2017).

In this research study, an embedded electronic device is designed to measure the concentration of Odor pollution at selected areas. The design of artificial olfactory electronic nose (Gongora et al., 2019; Erisman, 2001) incorporates most desirable industrial Odor sensors; TGS2602 Metal Oxide Semiconductor (MOS) type Sensor for detecting Hydrogen Sulfide (H2S), Ammonia (NH3), Volatile Organic Compounds (VOCs) and 110-601 Sulphur Dioxide (SO2) sensor, Solar harvesting unit for powering the portable electronic nose, Odor threshold level indicator, Communication network unit (Wi-Fi) for uploading processed data onto the IoT cloud storage and mobile application for retrieving the Odor concentration from IoT cloud, performing risk assessment based on standard threshold levels (EPA, 2021) and then providing the alert information to end users. Finally, the Data processor (Atmega328) coordinates and controls all the peripherals connected to the system, processes the sensor data and sends the sensed information to the Cloud. 


\section{MATERIALS AND METHODS}

\subsection{STUDY AREA}

The different odour emission sources in and around the Kuppam Town, Andhra Pradesh, India, selected for studying the Odour pollution and its Risk assessment based on standard odour threshold levels. The most commonly selected odour emission sources (areas) are; agriculture practices (fertilizer, pesticides), large livestock operations, poultry farms, fish market, drainages, Municipal Solid waste dumping yards \& public amenities like toilets of cinema hall, bus / railway stations, hospitals, shopping complex, etc.

Some of the Municipal Solid waste dumping yards, drainages, fish markets in Kuppam areas as shown in the Figure 1.

Figure 1. Study areas like fish market, landfills and drainages etc. Images taken at Kuppam.

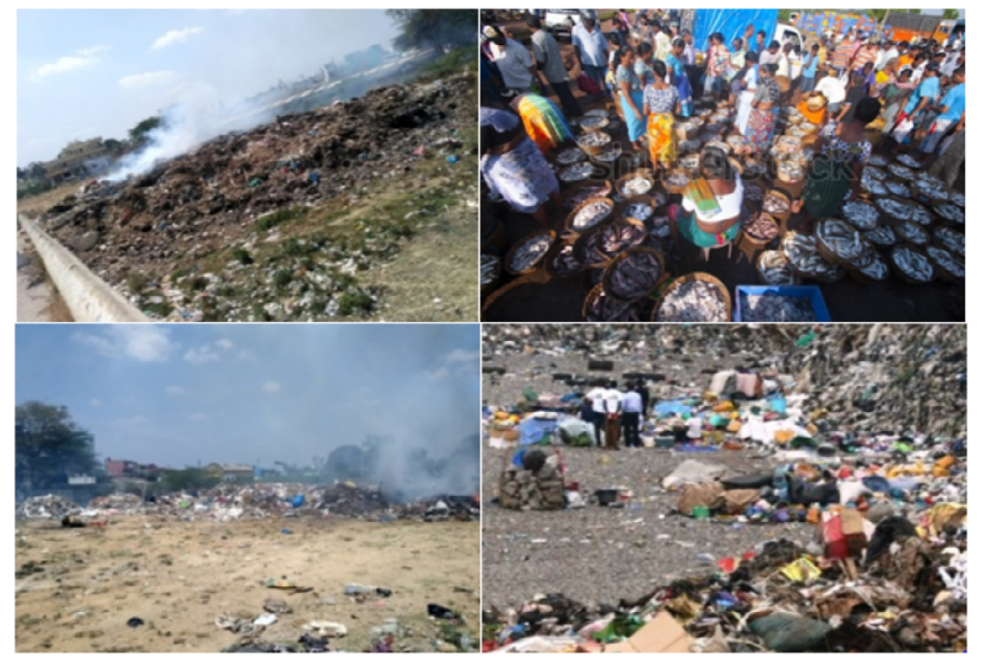

Source: own elaboration.

The selected study area in Kuppam, weather in the wet season is muggy and overcast, the dry season is partly cloudy, and it is hot year round. The temperature typically varies from $18^{\circ} \mathrm{C}$ to $38^{\circ} \mathrm{C}$, Average rainfall varies from $4 \mathrm{~mm}$ to $124 \mathrm{~mm}$, Extreme variation in the perceived humidity varies from $29 \%$ to $89 \%$ and the seasonal variation of the wind speed over the course of the year is $2.7 \mathrm{~m} / \mathrm{s}$ to $6.1 \mathrm{~m} / \mathrm{s}$ (Weather Spark, 2020). 


\subsection{METHODOLOGY}

The development of methods includes:

- Design of artificial olfactory Electronic device (E-Nose).

- Mathematical modelling.

- Measurement of Odour concentration \& Sampling.

- Data processing, Storage \& Remote Monitoring.

- Risk assessment \& Standard Guidelines.

The odour concentration were measured using artificial olfactory Electronic device called Electronic Nose from different sources of odour emission, risk assessment was done based on the standard safety and threshold concentration levels prescribed by like Occupational Safety and Health Administration (OSHA), National Institute for Occupational Safety and Health (NIOSH) (NIOSH, 2007; OSHA, 2011).

\subsubsection{DESIGN OF ARTIFICIAL OLFACTORY ELECTRONIC DEVICE (E-NOSE)}

In this research study, an embedded electronic device is designed to measure the concentration of odour pollution at selected areas. The design of artificial olfactory electronic nose incorporates most desirable industrial Odour sensors; TGS2602 Metal Oxide Semiconductor (MOS) type Sensor for detecting Hydrogen Sulphide (H2S), Ammonia (NH3), Volatile Organic Compounds (VOCs) and 110-601 Sulphur Dioxide (SO2) sensor, Solar harvesting unit for powering the portable electronic nose, Odour threshold level indicator, Communication network unit (Wi-Fi) for uploading processed data onto the IoT cloud storage and mobile application for retrieving the odour concentration from IoT cloud , performing risk assessment based on standard threshold levels and then providing the alert information to end users. Finally, the Data processor (Atmega328) coordinates and controls all the peripherals connected to the system, processes the sensor data and sends the sensed information to the Cloud. The artificial olfactory Electronic device (E-Nose) design block diagram is as shown in Figure 2. 
Figure 2. Block diagram of Proposed Electronic Node Design.

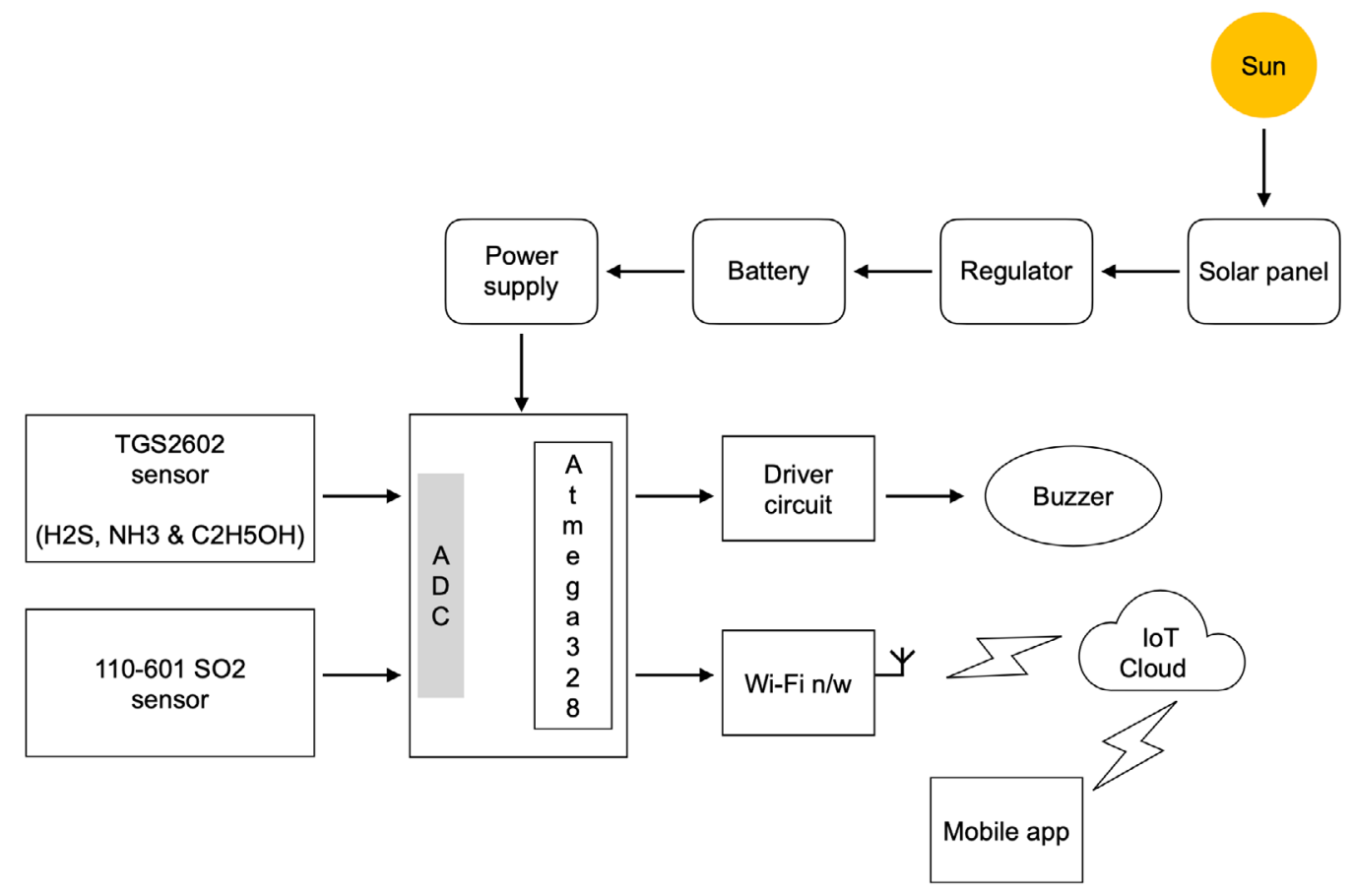

Source: own elaboration.

\subsubsection{MATHEMATICAL MODELLING}

The mathematical modelling involves the development the mathematical algorithms for calculating sensor coefficients (calculating sensor resistance (Ro) in fresh air, sensor resistance (Rs) in displayed gases at various concentrations) from the sensitivity curve of sensor datasheet and converting the analog output values of the odour sensors into Parts Per Millions (PPM) standard.

Sensor coefficients can be calculated in to ways either using straight line equation or using power Regression analysis.

To calculate the sensor coefficients using straight line equations sensitivity curve and the basic measuring circuit of the sensor is considered as shown in Figure 3. 
Figure 3. Basic measuring circuit of TGS2602 sensor.

$(+)$

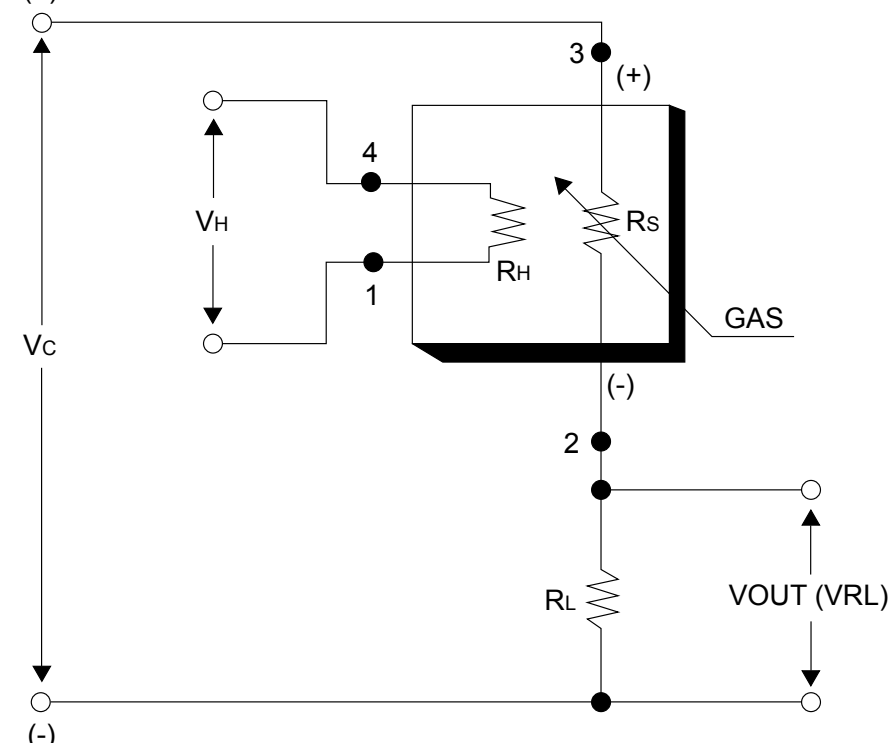

$(-)$

Source: TGS2602 Sensor Datasheet, FIGARO USA, INC.

The sensor resistance $\mathrm{R}$ s can be determined using Ohm's Law: $\mathrm{V}=\mathrm{I} \times \mathrm{R}$

from basic measuring circuit is output current is equal to: $\mathrm{I}=\mathrm{VG} /(\mathrm{Rs}+\mathrm{RL})$

Ro/RL: sensor resistance in the clean air.

Rs: sensor resistance at various concentrations of gases.

Then; Rs $=\left[\left(\mathrm{Vc}_{\mathrm{x}} \mathrm{RL}\right) / \mathrm{VRL}\right]-\mathrm{RL}$

Equation 1 will help us find the values of the sensor resistance for different gases. To calculate sensor resistance Ro, the value of the RS in fresh air needs to be determined. This is done by taking the average of analog readings from the sensor and converting it to voltage.

The sensitivity curve/graph of the sensor is in log-log scale, so the straight-line equation for finding coefficients is;

$y=m x+b$

Where: $\mathrm{y}$ : $\mathrm{Y}$ value on $\mathrm{Y}$ axis 

$\mathrm{x}$ : $\mathrm{X}$ value on $\mathrm{X}$ axis
$\mathrm{m}$ : Slope of the line
b: Y intercept

For a $\log -\log$ scale, the formula looks like; $\log (\mathrm{y})=\mathrm{m}^{*} \log (\mathrm{x})+\mathrm{b}$

Now to find the slope $(\mathrm{m}), 2$ points needs to be chosen from the sensitivity curve/graph.

The formula to calculate $\mathrm{m}$ is the following:

$$
\mathrm{y}=\mathrm{mx}+\mathrm{b}
$$

where: value of $\mathrm{x}$ : $\mathrm{X}$ value on $\mathrm{x}$-axis

value of $\mathrm{m}$ : Slope of line

b: Y interception Point on Graph $(\mathrm{x} 1, \mathrm{y} 1)(\mathrm{x} 2, \mathrm{y} 2)$

$$
\begin{aligned}
& \mathrm{m}=[\log (\mathrm{y})-\log (\mathrm{y} 0)] /[\log (\mathrm{x})-\log (\mathrm{x} 0)] \\
& \mathrm{b}=\log (\mathrm{y})-\mathrm{m} * \log (\mathrm{x}), \\
& \log (\mathrm{y})=\mathrm{m} * \log (\mathrm{x})+\mathrm{b},
\end{aligned}
$$

This is how the two coefficients $(\mathrm{m}, \mathrm{b})$ are calculated using straight lines equations of sensitivity curve.

Another method to calculate coefficients $(\mathrm{m}, \mathrm{b})$ is using power regression based digitizing software tool, which converts the image file showing the sensor graph/curve into digital numbers. The digitizer tool recovers the data points from sensor graphs. The calculated data points are usually used as input to other software applications or programming the controllers to measure gas concentrations accurately from the sensors.

After finding the Coefficients, slope $m$ and b using straight line equation method or power regression method from sensor gas sensitivity curve, finally calculating the gas concentration in ppm using the equation 3 ;

$$
\mathrm{X} \text { in } \mathrm{ppm}=10^{\wedge}((\log (\mathrm{Rs} / \mathrm{Ro})-\mathrm{b}) / \mathrm{m})
$$




\subsubsection{MEASUREMENT OF ODOR CONCENTRATION \& SAMPLING METHOD}

From decades mainly research studies on odor concentration measurement were based laboratory testing, which means collection of Odor samples from different test fields and then measuring concentration of different odor gases at the laboratory.

In our research study we developed a customized electronic device (E-Nose) using Different odor sensors to determine the concentration of various odor gases at selected areas. Before the development of odor sensing device, firstly, we selected study areas and visited to investigate problems persisted in and around the study areas due to odor pollution. Conducted real-time survey by interacted with the residents staying around the selected study areas with various questionnaires related to health issues, lifestyle, frequency of occurrence, duration, etc., Secondly, we developed a customized electronic device (E-Nose) for measuring odor concentration at the field under test. Thirdly, we carried the Autonomous E-Nose odor sensing device for measuring odor concentration at various selected areas. Repeated the measurements were done for many days and then uploaded the measured odor concentrations to IoT cloud for further studies and performing risk assessment based on the measured levels.

\subsubsection{DATA PROCESSING, STORAGE \& REMOTE MONITORING}

The data collection starts with the basic survey where the research study begins and continued till the real-time field measurement of odor concertation will be done, hence the data needs to be processed at various stages of the research development. The data processor reads odor levels from the odor sensors, then processes it by applying mathematical modelling algorithms to convert the output voltage levels into odor concentration in parts per million (ppm). After data processing, measured odor concentration data was uploaded to IoT cloud for storage and further studies. The data stored onto the IoT cloud helps us to further assess the data using user-friendly user interfaces like mobile/web applications or remote monitoring and decision-making purposes.

\subsubsection{RISK ASSESSMENT \& STANDARD GUIDELINES}

As we know that constant exposure to odor pollution causes many health issues, therefore risk assessment must be done comparing the measured odor concentration levels at various 
areas against the standard Threshold Limit Levels (TLV) of various Odor gases published by agencies like Occupational Safety and Health Administration (OSHA), National Institute for Occupational Safety and Health (NIOSH), American Conference of Governmental Industrial Hygienists (ACGIH) (NIOSH, 2007; OSHA, 2011; ACGIH, 2021). Risk assessment was performed based on the measured odor concentration and permissible Threshold Limit Levels (TLV). After assessment, if the concentration of measured odor gas exceeds threshold limit values, then an alert indication with symptoms will be displayed on user application.

Table 1 shows the Standard Threshold Limit Levels (TLV), 8-hour Time-weighted Average (TWA), Short Term Exposure Limit Values (STEL) and Immediately Dangerous to Life \& Health (IDLH),

Table 1. Threshold Limit values of various odor gases concentration in parts per million (ppm).

\begin{tabular}{|c|c|c|c|}
\hline Odor Gas & TLV-TWA & TLV-STEL & IDLH \\
\hline Ammonia (NH3) & 25 & 35 & 300 \\
\hline Hydrogen Sulfide (H2S) & 10 & 15 & 100 \\
\hline Sulphur Dioxide, SO2 & 2 & 5 & 100 \\
\hline
\end{tabular}

Sources: TLV-TWA and TLV-STEL data extracted from the 2005 Threshold Limit Values \& Biological Exposure Indices, copyright 2005 by the American Conference of Governmental Industrial Hygienists (ACGIH). IDLH values extracted from the NIOSH Pocket Guide to Chemical Hazards, 2004 published by the National Institute for Occupational Safety and Health (NIOSH).

\section{RESULTS AND DISCUSSIONS}

In this current research work, we followed new approach of measuring odor concentrations based on electronic devices rather than on human sensory olfaction methods. Figure 4 shows a self-powered portable electronic device (E-Nose) designed to measure the concertation of odour gases at selected areas.

In first phase we conducted real-time health survey of residents and peoples staying near the selected study areas like; waste dumping yard, Drainages, agriculture practices, livestock operations, industries and poultry forms. The survey involved the questionnaires in the form age, gender, type of health issue (disease), frequency of occurrence \& duration. In this sampling survey around 80 peoples were interacted and collected the information mentioned in the questionnaire. The real-time survey data is shown in Table 2. 
Figure 4. Proposed Odor Measuring Portable Electronic Hardware Device.

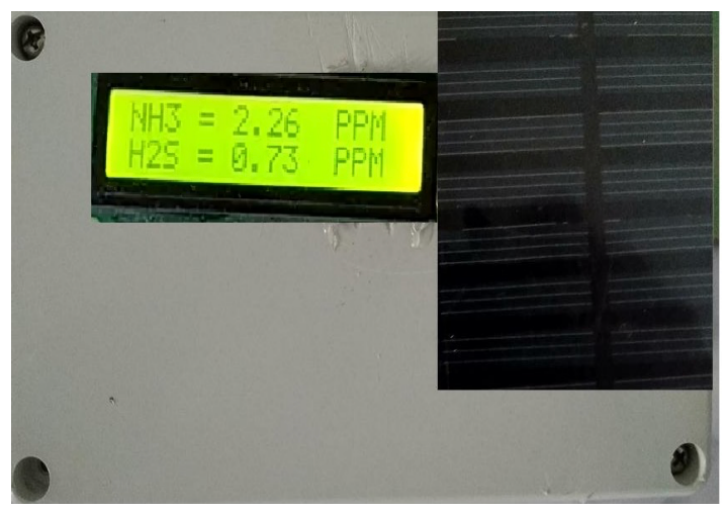

Source: own elaboration.

Table 2 gives information about real-time survey at different areas, various symptoms or health issues reported by interacting with peoples staying at the areas and proximity areas. Most of the peoples reported the frequency of occurrence \& duration of these symptoms is around 1 week to 1 month.

Table 2. Conducted Real-time Health survey data at different areas (Kuppam area).

\begin{tabular}{|c|c|c|}
\hline Study Area & Health Symptoms & No. of Health issues reported \\
\hline \multirow{4}{*}{ Waste Dumping Yard } & Nausea, Coughing & 35 \\
\hline & Headache, Loss of sleep & 40 \\
\hline & $\begin{array}{l}\text { Irritation (eyes, throat, nose) Respiratory } \\
\text { problems }\end{array}$ & 39 \\
\hline & Fatigue \& Dizziness & 37 \\
\hline \multirow{4}{*}{ Drainage at Residents } & Nausea, Coughing & 43 \\
\hline & Headache, Loss of sleep & 40 \\
\hline & $\begin{array}{l}\text { Irritation (eyes, throat, nose) Respiratory } \\
\text { problems }\end{array}$ & 38 \\
\hline & Fatigue \& Dizziness & 32 \\
\hline \multirow{4}{*}{$\begin{array}{c}\text { Agriculture practices } \\
\text { Pesticides } \\
\text { fertilizers }\end{array}$} & Nausea, Coughing & 53 \\
\hline & Headache, Loss of sleep & 49 \\
\hline & $\begin{array}{l}\text { Irritation (eyes, throat, nose) Respiratory } \\
\text { problems }\end{array}$ & 29 \\
\hline & Fatigue \& Dizziness & 42 \\
\hline \multirow{4}{*}{$\begin{array}{l}\text { Livestock Operations } \\
\text { Nausea, Coughing } \\
\text { Headache, Loss of } \\
\text { sleep }\end{array}$} & Nausea, Coughing & 33 \\
\hline & Headache, Loss of sleep & 30 \\
\hline & $\begin{array}{l}\text { Irritation (eyes, throat, nose) Respiratory } \\
\text { problems }\end{array}$ & 28 \\
\hline & Fatigue \& Dizziness & 22 \\
\hline
\end{tabular}

Source: own elaboration. 
In the second phase, we conducted real-time measurement of odour concentration at selected areas. The table III shows the measured odour concentrations of Ammonia (NH3), Hydrogen Sulphide (H2S) \& Sulphur Dioxide (SO2) by considering temperature, humidity and wind speed \& direction, measurement is conducted morning to evening at the every lhr duration.

Table 3. Conducted Real-Time measurement of odour concentration at different sites.

\begin{tabular}{|c|c|c|c|}
\hline Study Area & \multicolumn{3}{|c|}{ Ranges of Measured Odour Concentration in ppm } \\
\hline Waste Dumping Yard & $\mathrm{NH} 3$ & $\mathrm{H} 2 \mathrm{~S}$ & $\mathrm{SO} 2$ \\
\hline Drainage at Residents & $15-105$ & $0.5-12$ & $0.25-1.5$ \\
\hline Agriculture practices & $10-85$ & $1.5-11$ & $0.5-2.0$ \\
\hline Fertilizers, pesticides & $45-115$ & $2-15$ & $1.5-4.5$ \\
\hline Livestock Operations & $5-95$ & $0.85-8.5$ & $0.2-1.25$ \\
\hline
\end{tabular}

Source: own elaboration.

Table 3 shows the measured odour concentration at different sites, at waste dumping site NH3 levels ranges from 15-105 ppm, H2S levels ranges from 0.5 - 12ppm, SO2 levels ranges from $0.25-1.5 \mathrm{ppm}$. Drainage at Residents NH3 levels ranges from 10-85 ppm, $\mathrm{H} 2 \mathrm{~S}$ levels ranges from 1.5 - $11 \mathrm{ppm}, \mathrm{SO} 2$ levels ranges from $0.5-2.0 \mathrm{ppm}$. Agriculture practices Fertilizers, pesticides NH3 levels ranges from 45-115 ppm, H2S levels ranges from $2-15 \mathrm{ppm}$, SO2 levels ranges from $1.5-4.5 \mathrm{ppm}$. Livestock Operations NH3 levels ranges from 5-95 ppm, H2S levels ranges from 0.85 - 8.5 ppm, SO2 levels ranges from $0.2-1.25$ $\mathrm{ppm}$. The rage of odour concentrations at different sites are clearly showing exceed in its levels i.e 8-hr Time Weighted Average (TWA) Threshold Limit Value (TLV) and Short Time Exposure Limit (STEL) Threshold Limit Value (TLV) as shown in Table 2. According to OSHA, NIOSH and ACGIC regulation the symptoms or health issues associated with the measured concentration ranges are (ACGIH, 2021; NIOSH, 2011) nausea, coughing, headache, loss of sleep, irritation (eyes, throat, nose), respiratory problems, fatigue \& dizziness, etc.

Finally measured odour concertation levels are uploaded to IoT cloud and further studies. The data stored onto the IoT cloud helps us to further assess the health impacts associated with odour levels using user-friendly mobile/web applications. After risk assessment, if odour levels are exceeds the threshold limit values, then precautionary alert is generated as shown in Figure 5. IoT application displays Odour concentration levels in ppm at measures site on the map as well as in the dashboard. 
Figure 5. Design of loT Mobile Application.

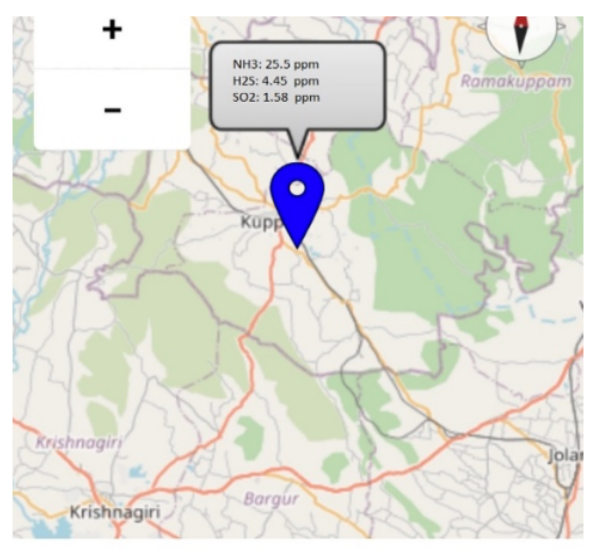

loT Latitude: 12.72149 loT Longitude: 78.36166

Ammonia (NH3): 25.5

Hydrogen Sulfide: 4.45

Sulphur Dioxide(SO2): 1.58

PRECAUSTIONS

Odour Threshold Exceeded:

8-hr Time Weighted Average, Threshold Limit Values(TLV)

of Odour concentration exceeded, continous exposure may

cause Nausea, Irritation, Headache, Coughing, Loss of

sleep etc.,

\section{$\square$}

\section{○}

$\triangleleft$

Source: Developed on MIT APP Inventor 2.

\section{CONCLUSIONS}

We successfully designed an OdorSense a solar-powered, portable handheld electronic device, and conducted the real-time measurement of odor gas concentrations at various study areas. The device has shown satisfactory results in measuring the odor levels. A realtime health survey has been conducted at selected study areas involving around 80 peoples in the sampling process based on questionnaires. After conducting the odor concentration measurement, a Risk assessment was performed to check the associated health issues based on the measured odor concentration and permissible Threshold Limit Values (TLV) i.e TLV-TWA and TLV-STEL. After the assessment, if the concentration of measured odor gas exceeds threshold limit values, then an alert indication with symptoms will be displayed on the user application. Hence a user-friendly system was developed to measure and assess the odor pollution at any application. 


\section{ACKNOWLEDGEMENTS}

The author of research paper would like to express gratitude to G. N. Kodanda Ramaiah, Professor \& Director R\&D, Kuppam Engineering College for supporting and guiding throughout the research work. Also grateful to the Dr. Rangaraju and Dr. Vijay Prakash, Doctoral Committee members or giving valuable suggestions or carrying out research work. Finally, I feel thankful to KEC management for the motivation and research facilities provided in the R\&D Centre in the Institution.

\section{REFERENCES}

Association Advancing Occupational and Environmental Health. (2021, February 24). Association Advancing Occupational and Environmental Health. AGGIH. https://www. acgih.org

Bax, G., Sironi, S., \& Capelli, L. (2020). How Can Odors Be Measured? An Overview of Methods and Their Applications. Atmosphere, 11(1), 92. https://doi.org/10.3390/ atmos 11010092

GDC - The National Institute for Occupational Safety and Health (NIOSH). (2007). https://www.cdc.gov/niosh/index.htm

Ceballos, D. M., \& Burr, G. A. (2012). Evaluating a Persistent Nuisance Odor in an Office Building. Fournal of Occupational and Environmental Hygiene, 9(1), D1-D6. https:/ / doi.org/10.1080/15459624.2012.635131

Elwell, D. L., Keener, H. M., Wiles, M. G., Borger, D. G., \& Willett, L. B. (2001). Odorous Emissions and Odor Control In Composting Swine Manure/Sawdust Mixes Using Continuous And Intermittent AERATION. Transactions of the ASAE, 44(5), 1307-1316. https://doi.org/10.13031/2013.6436

Deshmukh, S., Bandyopadhyay, R., Bhattacharyya, N., Pandey, R. A., \& Jana, A. (2015). Application of electronic nose for industrial odors and gaseous emissions measurement and monitoring - An overview. Talanta, 144, 329-340. https://doi. org/10.1016/j.talanta.2015.06.050 
Di, Y., Liu, J., Liu, J., Liu, S., \& Yan, L. (2013). Characteristic analysis for odor gas emitted from food waste anaerobic fermentation in the pretreatment workshop. Journal of the Air \& Waste Management Association, 63(10), 1173-1181. https://doi.org/ $10.1080 / 10962247.2013 .807318$

Erisman, J. (2001). Instrument development and application in studies and monitoring of ambient ammonia. Atmospheric Environment, 35(11), 1913-1922. https://doi. org/10.1016/s1352-2310(00)00544-6

Gongora, A., Jaenal, A., Ghaves, D., Monroy, J., \& Gonzalez-Jimenez, J. (2019). Urban Monitoring of Unpleasant Odors with a Handheld Electronic Nose. In 2019 IEEE International Symposium on Olfaction and Electronic Nose (ISOEN), 1-3. https://doi. org/10.1109/isoen.2019.8823219

Hayes, E. T., Curran, T. P., \& Dodd, V. A. (2006). A dispersion modelling approach to determine the odour impact of intensive poultry production units in Ireland. Bioresource Technology, 97(15), 1773-1779. https://doi.org/10.1016/j.biortech.2005.09.019

Occupational Safety and Health Administration. (2011). https://www.osha.gov

Ministry of Environment \& Forests, Government of India. (2007). Guidelines On Odour Pollution \& Its Control. Central Pollution Control Board (CPCB).

Misselbrook, T. H., Glarkson, G. R., \& Pain, B. F. (1993). Relationship Between Concentration and Intensity of Odours for Pig Slurry and Broiler Houses. Fournal of Agricultural Engineering Research, 55(2), 163-169. https://doi.org/10.1006/ jaer. 1993.1040

Nicolas, J., Graffe, F., \& Romain, A. G. (2006). Estimation of odor emission rate from landfill areas using the sniffing team method. Waste Management, 26(11), 1259-1269. https://doi.org/10.1016/j.wasman.2005.10.013

Pagans, E., Barrena, R., Font, X., \& Sánchez, A. (2006). Ammonia emissions from the composting of different organic wastes. Dependency on process temperature. Chemosphere, 62(9), 1534-1542. https://doi.org/10.1016/j.chemosphere.2005.06.044 
Sarkar, U., \& Hobbs, S. E. (2002). Odour from municipal solid waste (MSW) landfills. Environment International, 27(8), 655-662. https://doi.org/10.1016/s01604120(01)00125-8

Shinde, R. B., \& Sagar, M. G. (2017). Odour Reducing Technique in Field at Kurkumbh. International Journal of Engineering Research, 6(6), 341. https://doi.org/10.5958/23196890.2017 .00033 .2

Szulczyński, B., \& Gębicki, J. (2019). Electronic nose - an instrument for odour nuisances monitoring. E3S Web of Conferences, 100, 00079. https://doi.org/10.1051/ e3sconf/201910000079

Takano, T. (2014). The measurement of the offensive odor and application of the measurement technology to the smell in living. Fournal of Japan Association on Odor Environment, 45(1), 2-8. https://doi.org/10.2171/jao.45.2

United States Environmental Protection Agency. (2021, January 21). Reference guide to odor thresholds for hazardous air pollutants listed in the clean air. https://www.epa.gov/ laws-regulations

Weather Spark. (2020). Average Weather in Kuppam, India, Year Round. https://weatherspark. com/y/109403/Average-Weather-in-Kuppam-India-Year-Round

Wenjing, L., Zhenhan, D., Dong, L., Jimenez, L. M. G., Yanjun, L., Hanwen, G., \& Hongtao, W. (2015). Characterization of odor emission on the working face of landfill and establishing of odorous compounds index. Waste Management, 42, 74-81. https://doi.org/10.1016/j.wasman.2015.04.030

Zhu, Y., Zheng, G., Gao, D., Ghen, T., Wu, F., Niu, M., \& Zou, K. (2016). Odor composition analysis and odor indicator selection during sewage sludge composting. Journal of the Air \& Waste Management Association, 66(9), 930-940. https://doi.org/10. 1080/10962247.2016.1188865 